This item was submitted to Loughborough's Research Repository by the author.

Items in Figshare are protected by copyright, with all rights reserved, unless otherwise indicated.

\title{
Ultra-high enhancement in the toughness of polyethylene by exfoliated natural clay nanosheets
}

PLEASE CITE THE PUBLISHED VERSION

http://dx.doi.org/10.1002/app.41314

PUBLISHER

(c) Wiley Periodicals

VERSION

NA (Not Applicable or Unknown)

\section{PUBLISHER STATEMENT}

This work is made available according to the conditions of the Creative Commons Attribution 4.0 International (CC BY 4.0) licence. Full details of this licence are available at: http://creativecommons.org/licenses/ by/4.0/

\section{LICENCE}

CC BY-NC-ND 4.0

\section{REPOSITORY RECORD}

Cai, Dongyu, and Mo Song. 2015. "Ultra-high Enhancement in the Toughness of Polyethylene by Exfoliated Natural Clay Nanosheets”. figshare. https://hdl.handle.net/2134/17914. 


\title{
Ultra-high enhancement in the toughness of polyethylene by exfoliated natural clay nanosheets
}

Dongyu Cai and Mo Song*

Department of Materials, Loughborough University, Loughborough, Leicestershire, United Kingdom, LE11 3TU

*corresponding author. Tel.:+44(0)1509223160; Fax:+44(0)1509223949

Email address: $\underline{\text { m.song@lboro.ac.uk }}$

\begin{abstract}
The full exfoliation of inorganic natural clay was engineered in a non-polar polyethylene following a novel and simple method without the involvement of any chemical modification to the surface of silicate layers. It was found that the toughness of polyethylene was unprecedentedly improved by nearly 5 times with $0.5 \mathrm{wt} \%$ natural clay nanosheets. Moreover, this novel exfoliated system demonstrated a new understanding on the nano-toughening mechanism and it pointed out the promising application of these nanocomposites in dynamic environments.
\end{abstract}

Keywords: Exfoliated clay, Nanocomposites, Mechanical Properties, Toughness

\section{Introduction}

The combination of nanomaterials and polymer has led to the generation of a new group of interesting materials well-known as polymer nanocomposites (PNCs).[1-3] Two-dimensional clay nanosheets made historical contribution to the PNCs based on the fact that the term "PNCs" was created as nylon/clay nanocomposites came out as the first commercial products in 1990.[4] The benefits of two-dimensional nanomaterials for the PNCs are being further promoted due to hot graphene research in recent years.[5,6] Currently, graphene is winning a great deal of favor in the field of the PNCs due to its exciting physical properties.[7,8] When 
the application of graphene-based composites remains a big challenge in industrial scale due to high cost of graphene, commercial clay materials have served the PNCs for many years. Commerical clay products are commonly made by chemically modifying natural clay minerals. Natural clay minerals have rich resources in the world of nature, but they cannot be well-dispersed in organic polymers particularly non-polar ones such as polyolefin due to inorganic-organic incompatibility. Polyolefin is a group of leading thermoplastic materials that has been explored with a variety of commercial applitions for a long history. To broad the applications of polyolefin, it has generated a great deal of interests in using strong nanofillers to enhance mechanical performance of polyolefins. Conventionally, chemical modification is popularly applied to the surface of natural clay layers to assist the dispersion of layered clays to form intercalated or exfoliated structure in polymeric matrices.[4] However, the use of chemical modifiers produces huge impact on manufacturing cost, safety, processing and recycling of the PNCs. In this communication, it was reported that full exfoliation of a natural clay was acheived by a simple method in high density polyethylene (HDPE) that is a typical non-polar polyolefin with poor wetting ability and inactive backbone. The chemical modification of nanoclay was not involved in this process, which demonstrated the advantages in manufacturing clay-based PNCs in future. Furthermore, it was found that the HDPE was significantly toughened by these unmodified clay nanosheets, and meanwhile nano-toughening mechanism was discussed to have new understanding in the system of nanofilled semi-crystalline polymers.

\section{Experimental}

\subsection{Fabrication of exfoliated HDPE/clay nanocomposites}

The natural hectorite clay (Benton ${ }^{\circledR} \mathrm{HC}$ ) and HDPE powders was supplied by Elementis Specialties (Belgium) and ICO polymer Ltd (UK), respectively. The method for making exfoliated HDPE/clay nanocomosites was involved with the steps of (1) providing a mixture 
of a liquid such as water and the clay, in which the clay is dispersed in the liquid, and treating the mixture with sonication for half an hour to ensure that the clay is exfoliated; (2) contacting HDPE powders with the mixture of liquid and exfoliated clay, at an elevated temperature at which the surface of the polymer particles is modified to enhance adhesion of the clay to the polymer particles; (3) then separating the resulting polymer particles coated with exfoliated clay nanosheets from the liquid by drying the mixture made in step (2) at $70^{\circ} \mathrm{C}$ in an oven; (4) finally dried HDPE/clay powders were fed into a Haake Polylab mixer (Thermo Scientific) at $170^{\circ} \mathrm{C}$ for $5 \mathrm{~min}$ to form the exfoliated HDPE/clay nanocomposites.

\subsection{Characterization}

X-ray diffraction (XRD) patterns were obtained using Philip-X' Pert X-ray diffractometer (anode $40 \mathrm{kV}$, filament current $35 \mathrm{~mA}$ ) with nickel-filtered $\mathrm{CuK}_{\alpha}(\lambda=0.1542 \mathrm{~nm})$ radiation at a scan speed of $1^{\circ} \mathrm{min}^{-1}$. Transmission electron microscopy (TEM) analysis was conducted using a JEOL $2100 \mathrm{FX}$ instrument. The nanocomposite samples were microtomed to the slices of 100-150nm thickness using Huxley-Pattern Ultra-microtome (Cambridge Scientific instruments Ltd, UK), and then placed into standard TEM copper grids. Tensile tests were performed on the specimen (gauge length=25mm) using a Hounsfield tensile tester (Hounsfield test equipment Ltd, UK) at a crosshead rate of $50 \mathrm{~mm} / \mathrm{min}\left(0.03 \mathrm{~s}^{-1}\right)$ and $250 \mathrm{~mm} / \mathrm{min}\left(0.15 \mathrm{~s}^{-1}\right)$, respectively. Five specimens were tested for each samples. Nonisothermal crystallization was performed using a TA Instrument DSC 2920 calorimeter. 10mg sample was melted at $170^{\circ} \mathrm{C}$ for 2 min to ensure the complete removal of pre-existing crystals. Afterward, the melted sample was cooled to $20^{\circ} \mathrm{C}$ at a rate of $5^{\circ} \mathrm{C} / \mathrm{min}$ and then heated to $170^{\circ} \mathrm{C}$ at a rate of $5^{\circ} \mathrm{C} / \mathrm{min}$. Reflective optical microscopy (MeF3, Reichert-Jung, Wien, Austria) was used to image the surface of the sample directly after tensile tests. 


\section{Results and discussion}

Firstly, XRD and TEM techniques were both utilized to prove the exfoliation of the clay in the HDPE matrix. Figure 1a shows the XRD patterns of the natural hectorite clay and exfoliated HDPE/clay nanocomposites. The layered structure of the natural hectorite clay is reflected by the diffraction peak of $7.5^{\circ}$. The vanishing of this peak in the XRD patterns of the nanocomposites indicates the destruction of layered structure and the exfoliation of the clay in the HDPE matrix. However, a very tiny bumping peak is observed around $5^{\circ}$ at $2 \mathrm{wt} \%$ clay. It means a highly exfoliating state is acheived while a small proportion of clays are intercalated due to the factor of clay concentration. Figure 2(a and b) show the TEM images of the HDPE/(0.5wt\%)clay in the HDPE matrix, in which clay monosheets are clearly observed. Figure 2(c and d) present an intercalated clay with layered structure in the HDPE matrix with $2 \mathrm{wt} \%$ clay. It could be claimed that full or high exfoliation of the natural clay in the HDPE matrix was achieved by our method without any chemical modification. 

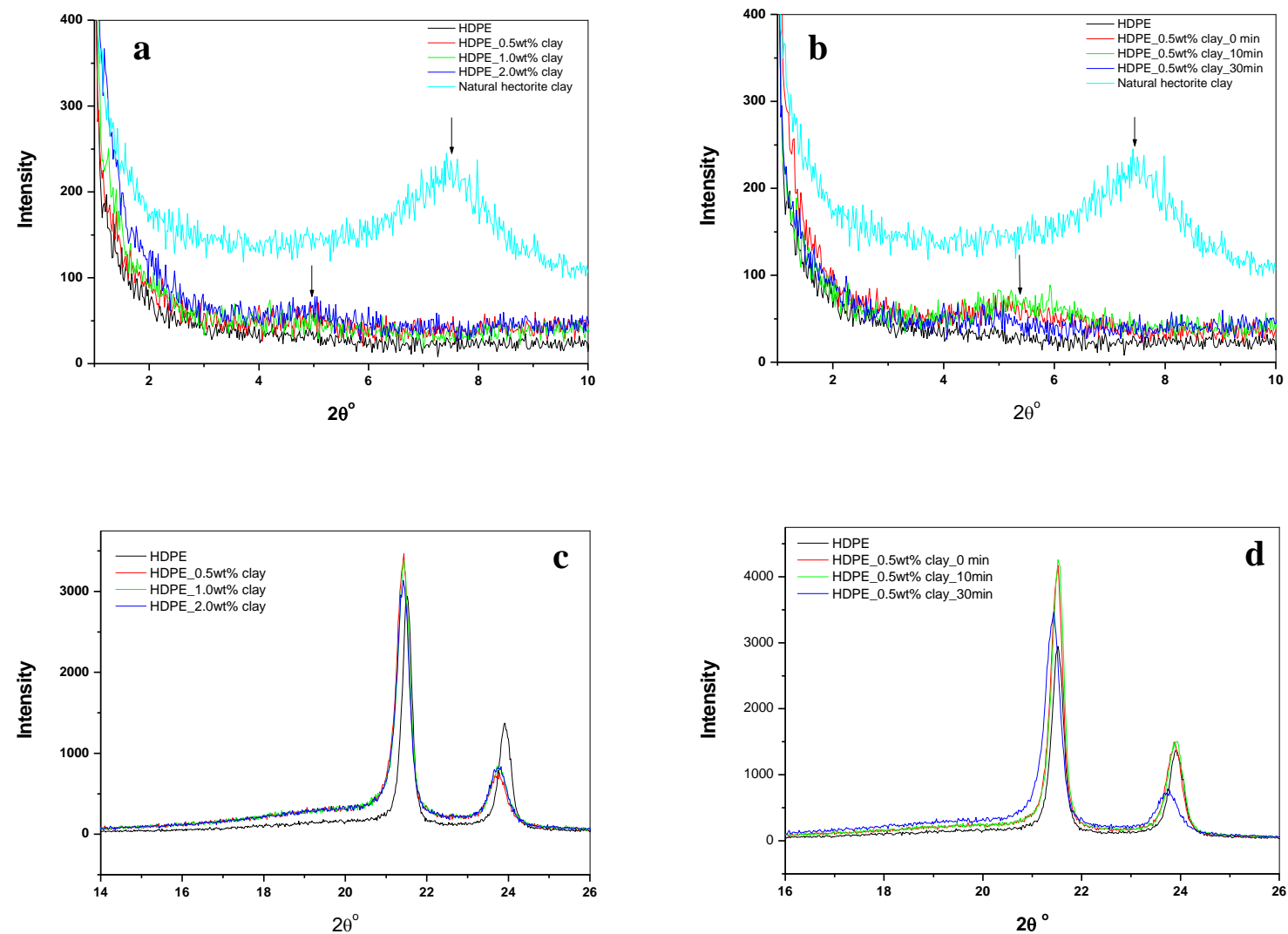

Figure 1. XRD patterns of $(\mathrm{a}, \mathrm{c})$ the exfoliated HDPE/clay nanocomposites with $0.5 \mathrm{wt} \%$, $1 \mathrm{wt} \%$ and $2 \mathrm{wt} \%$ natural clay nanosheets, and $(\mathrm{b}, \mathrm{d})$ the HDPE/(0.5wt\%)clay nanocomposites treated with different sonication time. 

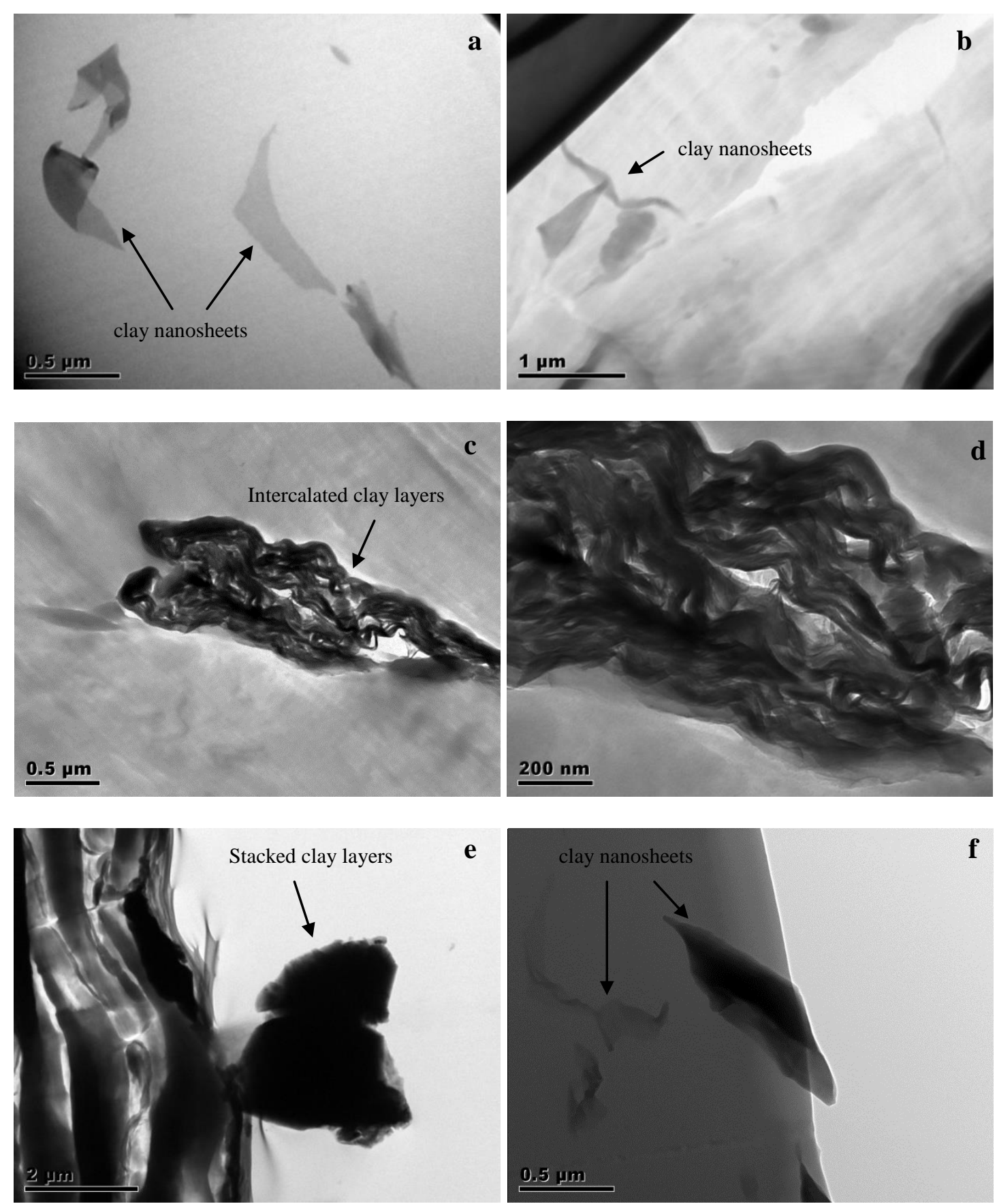

Figure 2. TEM images of $(a, b)$ the exfoliated HDPE/(0.5wt\%) clay nanocomposite, $(\mathrm{c}, \mathrm{d})$ the exfoliated HDPE/(2wt\%)clay nanocomposite, and (e,f) non-exfoliated HDPE/(0.5wt\%)clay nanocomposite without sonication.

It has been widely recognized that the nanofillers can make substantial contribution to the stiffness of polymers.[9,10] But the nano-toughening of polymers is much more complex, particularly for semi-crystalline polymers with two-phase microstructures.[11] It is well- 
known that the toughness of semi-crystalline polymer is related to the rate of external deformation and enviromental temperature. Toughening semi-crystalline polymer by microsized hard particles was experimentally discovered by Argon and his coworkers.[12] The toughening effect of hard particles was attributed to the oriented polymer crystalline layers induced around the hard particles. These oriented layers with reduced plastic shear resistance initiated the debonding of the hard particles from the polymeric matrix and the formation of cavity, reuslting in the improvement in the toughness. When it comes to nanofillers, the nanofillers with higher surface energy will form stronger adhesion with the matrix than that of micro-sized fillers and the debonding of the nanofillers from the matrix become more difficult. This is why the nanofillers generally show modest impact on the toughness of semi-crystalline polymers, sometimes even make the situation worse.[11] However, nano-toughening effect can be found in some cases providing that the interface is specially tailored. If the interaction between the nanofillers and the matrix is signficantly enhanced via surface modification of the nanofillers, the improvement of toughness results from the substantial energy dissipation taking place during the debonding of the nanofillers from the matrix.[13] This circumstance is generally observed at the low loading of nanofillers in which the stiffness and strength of polymers is greatly increased with limited loss in plasticity.[14,15] In addition, the improvement of the toughness is brought by the changed crystalline structure of polymers resulting from the nanofillers such as the formation of ductile fiber-like crystal.[16,17] The improved toughness is mainly due to the substantial increase in the plasticity of polymers rather than the stiffness. In some specific cases,[18] it has been found that the mobility of nanofiller in polymeric matrices facilitated the enhancement in the energy dissipation and plasticity. It was indicated that the mobility was driven by softening the matrices, therefore this nano-toughening mechanism was only available when the materials were tested above glass transition temperature. In this study, it was demonstrated that the exfoliated natural clay nanosheets provided a new route to toughen semi-crystalline polymers as it was considered 
that a very weak interface formed due to inorganic-organic compatibility could benefit the debonding of the clay nanosheets from the matrix, and therefore resulted in the increase in the energy dissipation.

Tensile tests were carried out at two different strain rates of $0.03 \mathrm{~s}^{-1}$ and $0.15 \mathrm{~s}^{-1}$ to evaluate the toughness of the exfoliated HDPE/clay nanocomposites. As shown in Figure 3a, exfoliated clay nanosheets fails to toughen the HDPE at the low strain rate of $0.03 \mathrm{~s}^{-1}$. The HDPE performs as typical ductile materials with large plastic deformation because polymer chains have enough time to reptate to dissipate external stress and avoid the concentration of internal stress under low strain rate extension. The mechanical strength of the HDPE seems to be decreased by the clay nanosheets as the reduction in tensile modulus and yield stress is illustrated from the strain-stress curves. Figure $3 b$ shows the strain-stress curves at the higher strain rate of $0.15 \mathrm{~s}^{-1}$. The HDPE performs like a brittle material because there is no enough time for the reptation of polymer chains to take place. The average values summaried in Figure $3 \mathrm{~d}$ indicate that the toughness of the nanocomposites with $0.5-2 \mathrm{wt} \%$ clay nanosheets is nearly 6 times that of pure HDPE. Apparently, the exfoliated nanocomposites exhibit ductile behavior in comparison with brittle HDPE under high strain rate extension. As disclosed in experimental section, half an hour sonication is the key step for ensuring the exfoliation of clay nanosheets in our method. A broad Peak centered at $5.5^{\circ}$ can be seen in the XRD patterns in Figure $1 \mathrm{~b}$ as the sonication time is shortened or no sonication is applied. The TEM images in Figure 2e also show that the natural clay cannot be completely exfoliated into single layer nanosheets in the HDPE matrix without proper sonicating treatment. As shown in Figure $2 \mathrm{f}$, it should be admitted that a few of exfoliated clay nanosheets can be produced in the HDPE matrix even without the ultrasonic treatment. However, tensile stress-strain curves in Figure $3 \mathrm{c}$ reveal that the tougheness of the HDPE fails to witness any improvement as the full exfoliation of the clay is not achieved. Therefore, fully or highly exfoliating natural clay into single layer nanosheets is a critical condition for switching on nano-toughening effect in the 
nanocomposites. After being stretched by the tensile tester, the samples were analyzed by reflective optical microscopy. The optical images in Figure 4 clearly show that a large number of micro-cracks are induced by the exfoliated clay nanosheets during tensile extension, but the formation of micro-cracks is hardly found in the pure HDPE. It is not questionable that the formation of micro-cracks should be the secrect of the enhanced energy dissipation of the nanocomposites under external deformation. Now the question is that how these micro-cracks are formed in presence of the exfoliated clay nanosheets. As discussed before, the interface is one of the main issues determining the nano-toughening effect. Here, it is worth investigating the interface in this novel system involved with exfoliated clay nanosheets.

It is our belief that interaction is very weak in this exfoliated system because the clay nanosheets with inorganic surface are not compatible with the organic matrix. It could be deduced by the reduction in the tensile modulus of exfoliated nanocomposites. It is assumed that the formation of PE crystallites nucleated by the exfoliated clay nanosheets may be the only chance for engineering a strong interface. DSC technique was used to measure the crystallization behavior of the exfoliated HDPE/clay nanocomposites at a cooling and heating rate of $5^{\circ} \mathrm{C} / \mathrm{min}$. Figure $5(\mathrm{a}$ and $\mathrm{b})$ shows that the exfoliated clay nanosheets impose negligible influence on the crystallization and melting behaviuor of the HDPE, indicating that the crystalline interface is not formed. XRD technique was used to study the crystalline structure of the HDPE/clay nanocomposites. The reflection at $2 \theta=21.5^{\circ}$ and $23.9^{\circ}$ corresponds to the index of refraction [110] and [200] planes of the orthorhombic unit cell in HDPE crystals, respectively.[19] Figure 1(c and d) discloses that the characteristic peaks shifts to lower position by $\sim 0.2^{\circ}$ and also are broadened in all exfoliated systems, whilst non-exfoliated systems hardly witnesses any change. It implies that no new crystalline structure is formed, but the integrity of crystalline phases is slightly altered by the exfoliated clay nanosheets. This may explain reduced yield stress of the nanocomposites because the yield stress is related to the inter-attraction between crystalline lamella. As the interface is engineered to be extremely 
weak, it is not difficult to understand that the interfacial debonding become easy and results in the formation of micro-cracks to avoid the concentration of internal stress.
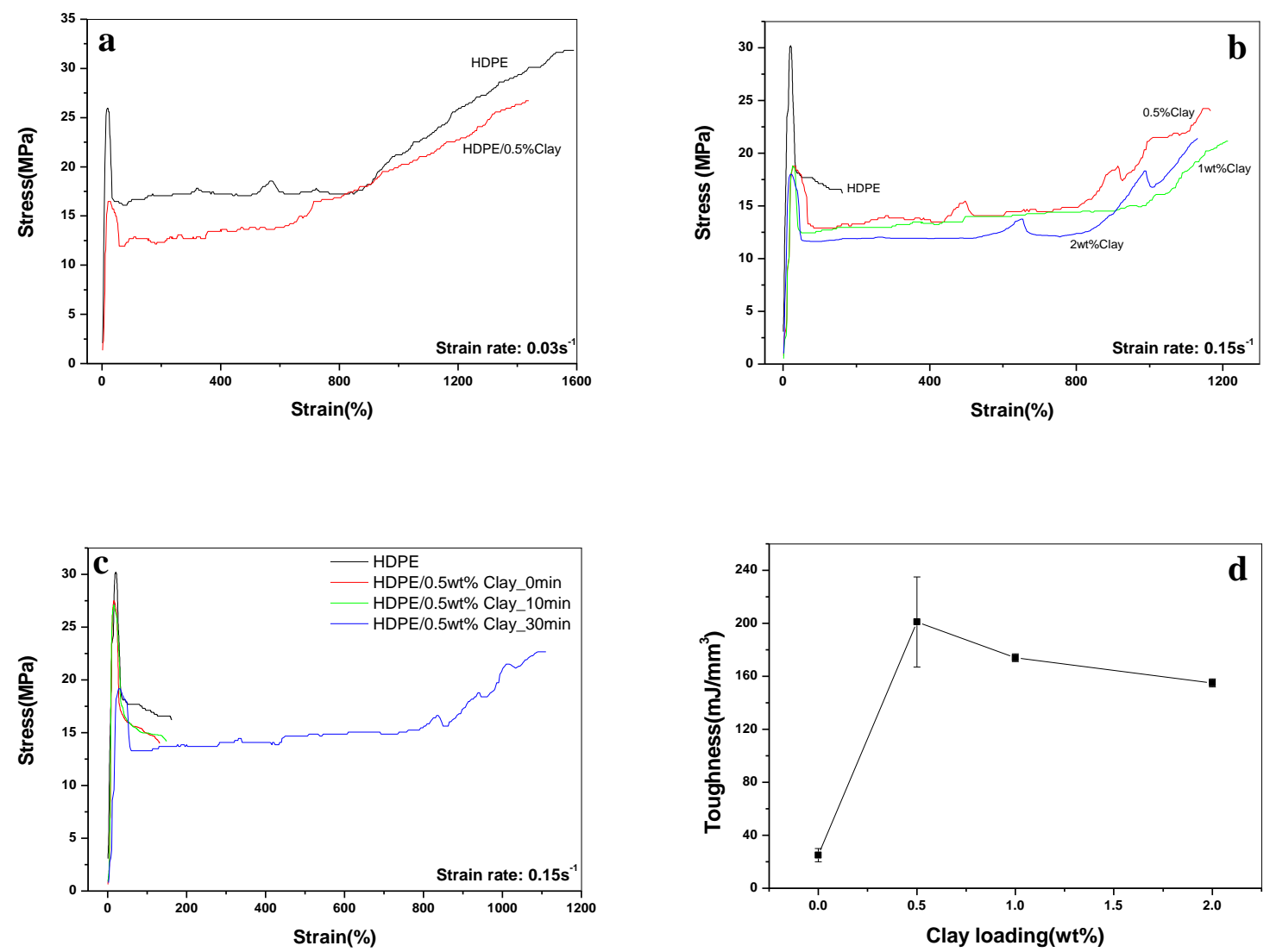

Figure 3. Tensile properties of the HDPE/clay nanocomposites. (a,b) stress-strain curves of the exfoliated HDPE/clay nanocomposites (a:strain rate $=0.03 \mathrm{~s}^{-1}$; b: strain rate $=0.15 \mathrm{~s}^{-1}$ ); (c) stress-strain curves of the HDPE/(0.5wt\%)clay nanocomposites against sonication time (strain rate $\left.=0.15 \mathrm{~s}^{-1}\right)$; (d)The average toughness (the area under stress-strain curves) of the exfoliated HDPE/clay nanocomposites against clay loading at the strain rate of $0.15 \mathrm{~s}^{-1}$. 

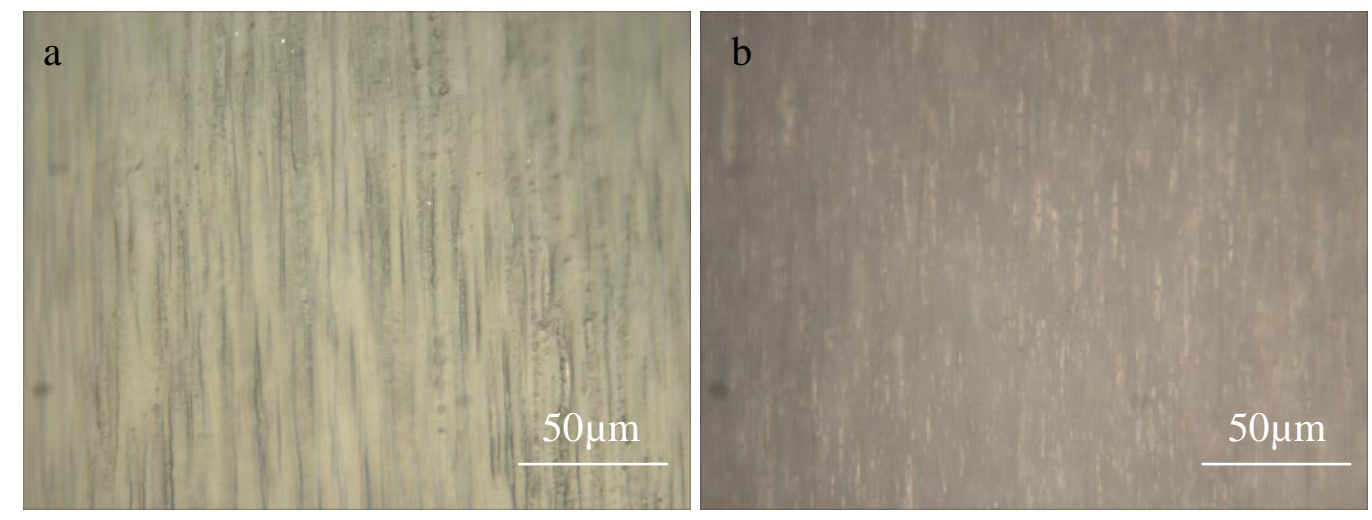

Figure 4. Optical images of (a) the HDPE, (b) the exfoliated HDPE/(0.5wt\%)clay nanocomposite after tensile extension at a strain rate of $0.15 \mathrm{~s}^{-1}$
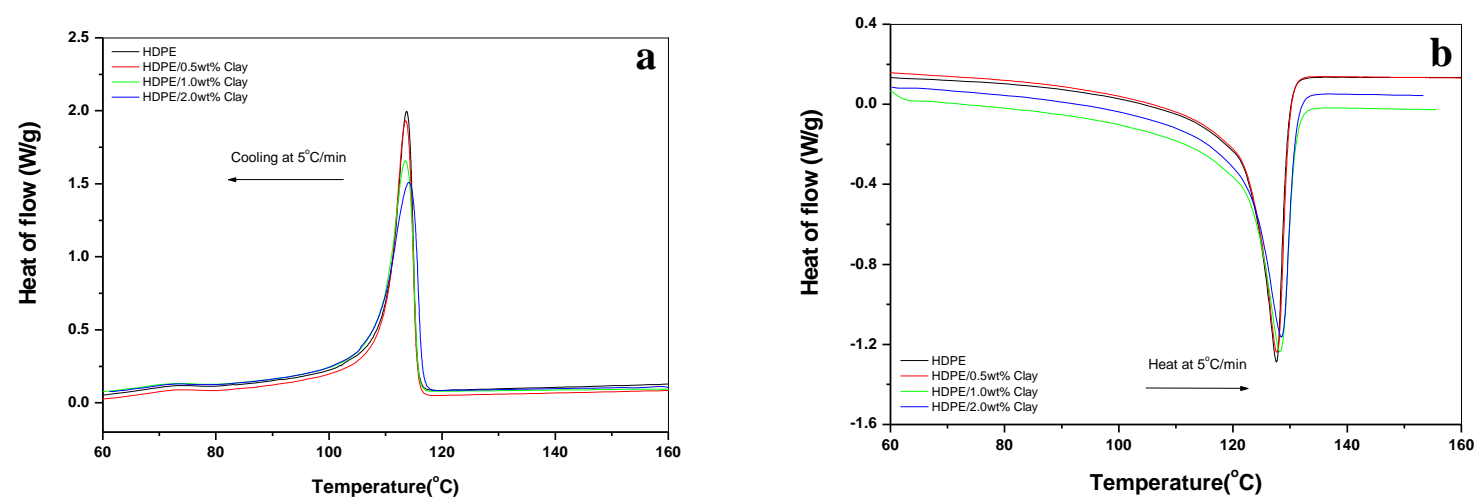

Figure 5. DSC curves of the exfoliated HDPE/clay nanocomposites at a cooling and heating rate of $5^{\circ} \mathrm{C} / \mathrm{min}$.

\section{Conclusions}

This study disclosed that a natural clay could be exfoliated in a non-polar HDPE matrix following a simple method without using any chemical treatment. The toughness of exfoliated HDPE/clay nanocomposites was substantially increased in comparion with that of the pure HDPE at high strain rate. This exfoliated system had a weak interface due to the inorganic characteristic of the clay nanosheets. A possible mechanism was disscused to understand clayenhanced energy dissipation in this exfoliated system, which was due to the formation of micro-cracks resulting from the debonding of the weak interface with low shear strength. In this system, the exfoliated natural clay nanosheets increased the plasticity but decreased the 
stiffness of the matrix. It was an interesting phenomenon that was not consistent with the common reinforcing effect of hard nanoparticles. It was believed that this system provided new platform to understand nano-toughening mechanism and would offer a new angle for designing nanocomposite materials.

\section{References}

1. Manias E. Nanocomposites: Stiffer by design. Nature Mater 2007;6:9-11.

2. Byrne MT, Gun'ko YK. Recent advances in research on carbon nanotube-polymer composites. Adv Mater 2010;22:1672-1688.

3. Ray SS, Okamoto M. Polymer/layeredsilicate nanocomposites: a review from preparation to processing. Prog Polym Sci 2003;28:1539-1641.

4. Okada A, Usuki A. Twenty Years of polymer-clay nanocomposites. Macromol Mater Eng 2006;291:1449-1476.

5. Ramanathan T, Abdala AA, Stankovich S, Dikin DA, Herrera-Alonso M, Piner RD, Adamson DH, Schniepp HC, Chen X, Ruoff RS, Nguyen ST, Aksay IA, Prud'Homme RK, Brinson LC. Functionalized graphene sheets for polymer nanocomposites. Nature Nanotechnol 2008;3:327-331.

6. Stankovich S, Dikin DA, Dommett GHB, Kohlhaas KM, Zimney EJ, Stach, EA, Piner RD, Nguyen ST, Ruoff RS. Graphene-based composite materials. Nature 2006;442:282-286.

7. Cai D, Song M. Recent advance in functionalized graphene/polymer nanocomposites. J Mater Chem 2010;20:7906-7915.

8. Kim H, Abdala AA, Macosko CW. Graphene/Polymer Nanocomposites. Macromolcules 2010;22:3441-3450.

9. Coleman JN, Khan U, Blau WJ, Gun'ko YK. Small but strong: A review of the mechanical propertiesof carbon nanotube-polymer composites. Carbon 2006;44(9):1624-1652. 
10. Coleman JN, Khan U, Gun'ko YK. Mechanical reinforcement of polymers using carbon nanotubes. Adv Mater 2006;18(6):689-706.

11. Chen B, Evans JRG. Impact strength of polymer-clay nanocomposites. Soft Matter 2009;5:3572-3584.

12. Bartczak Z, Argon AS, Cohen RE, Weinberg M. Toughness mechanism in semicrystalline polymer blends II. High-density polyethylene toughened with calcium carbonate filler particles. Polymer 1999;40:2347-2365.

13. Sun L, Gibson RF, Gordaninejad F, Suhr J. Energy absorption capability of nanocomposites: a review. Compos Sci Technol 2009;69:2392-2409.

14. Coleman JN, Cadek M, Blake R, Nicolosi V, Ryan KP, Belton C, Fonseca A, Nagy JB, Gun'ko YK, Blau WJ. Adv Func Mater 2004;14(8):791-798.

15. Cai D, Yusoh K, Song M. The mechanical properties and morphology of a graphite oxide nanoplatelet/polyurethane composite. Nanotechnology 2009;20(8):85712.

16. Rafiq R, Cai D, Jin J, Song M. Increasing the toughness of nylon 12 by the incorporation of functionalized graphene. Carbon 2010;48:4309-4314.

17. Shah D, Maiti P, Gunn E, Schmidt DF, Jiang DD, Batt CA, Giannelis, EP. Dramatic enhancements in toughness of polyvinylidene fluoride nanocomposites via nanoclay-directed crystal structure and morphology. Adv Mater 2004;16:1173-1177.

18. Shah D, Maiti P, Jiang DD, Batt CA, Giannelis EP. Eeffect of nanoparticles mobility on toughness of polymer nanocomposites. Adv Mater 2005;17(5):525-528.

19. Uehara H, Nakae M, Kanamoto T, Ohtsu O, Sano A, Matsuura K. Structural characterization of ultrahigh-molecular-weight polyethylene reactor powders based on fuming nitric acid etching. Polymer 1998;39:6127-6135. 